\title{
O DESAFIO DO ENSINO DE FILOSOFIA COM OS JOVENS DO ENSINO MÉDIO
}

\section{THE CHALLENGE OF TEACHING PHILOSOPHY WITH YOUNG PEOPLE OF $\mathrm{HIGH} \mathrm{SCHOOL}$}

\author{
Rozilene Vizzotto'
}

Resumo: $O$ artigo propõe pensar o ensino de Filosofia com os jovens, considerando os interesses em meio à cultura midiática e imagética, a qual compõem suas vivências existenciais na contemporaneidade, pois consideramos que a Filosofia somente se torna significativa à medida que o seu ensino seja pautado, metodologicamente por princípios que enfatizem a importância da investigação e problematização conceitual de temas filosóficos e que tais princípios estejam implicados na experimentação filosófica. Nesse sentido, cabe a pergunta: É possível filosofar com os jovens do ensino médio? Para responder a esse questionamento, objetivamos investigar a possibilidade do exercício filosófico com os jovens, considerando as condições socioculturais e quais são os possíveis modos do exercício filosófico no contexto da escola básica. Sabemos que a atividade filosófica requer leitura atenta desde o surgimento do problema filosófico até a sua solução. A escrita filosófica exige uma atitude de espreita à criação conceitual. Para tanto, o professor de filosofia precisa definir sua prática, propondo a experimentação filosófica mediada pelas tecnologias de comunicação e informação, a arte e o cinema, considerando que tais dispositivos são possibilidades de conexão entre o objetivo de tratar o problema filosófico e a cultura da imagem e do que resulta da relação dos jovens com o universo das redes sociais midiáticas.

Palavras-Chave: Ensino de Filosofia; Cultura Contemporânea; Tecnologias de Comunicação e de Informação.

\begin{abstract}
The article proposes to think the teaching of Philosophy with the young, considering the interests in the mediatic and imagistic culture, which compose their existential experiences in contemporaneity, since we consider that Philosophy only becomes meaningful as its teaching is guided, methodologically by principles that emphasize the investigation and conceptual problematization of philosophical subjects and that such principles are implied in the philosophical experi-
\end{abstract}


mentation. So the question is: is it possible to philosophize with high school youth? In order to answer this question, we aim to investigate the possibility of the philosophical exercise with the young, considering the sociocultural conditions and the possible ways of the philosophical exercise in the context of the basic school. Philosophical activity requires careful reading from the emergence of the philosophical problem to its solution. Philosophical writing demands a lurking attitude to conceptual creation. The philosophy teacher must define his practice, proposing the philosophical experimentation mediated by the technologies of information and communication, art and cinema, considering that such devices are possibilities of connection between the objective of dealing with the philosophical problem and the culture of the image and the wich results from the relationship of young to the universe of media social networks.

Keywords: Teaching of Philosophy; Contemporaneity Culture; Communication and Information Technologies.

\section{INTRODUÇÃO}

Atualmente, nós, professores de Filosofia, que atuamos no contexto da escola de ensino médio, temos encontrado dificuldades em trabalhar a Filosofia enquanto disciplina do currículo, pois, além da mesma ter sido, por longo período, negada enquanto parte do elenco das disciplinas obrigatórias, acresce a essa situação, a inexistência de uma cultura de apreço e interesse por esta área de saber. Em decorrência, o que se percebe é a afirmação de que a mesma, em muitos momentos, é entendida como atividade de ensino monótona, "chata" e sem utilidade prática para a vida. A atividade filosófica demanda leitura atenta, paciência, interpretação, concentração, reflexão, problematização, produção conceitual, e ao mesmo tempo, sabemos que o que subjaz a cultura contemporânea geralmente nos encaminha para o sentido oposto, ou seja, velocidade e superficialidade das informações e da comunicação.

Diante disso nos questionamos: É possível a atividade filosófica com os jovens de hoje, oriundos de uma cultura midiática e imagética? De que modo é possível esta atividade filosófica? Como despertar a paixão pelo filosofar neste jovem que tem tantas outras atividades que lhe chamam mais a atenção do que a filosofia?

Este trabalho tem por objetivo investigar a possibilidade da atividade filosófica com os jovens do Ensino Médio, tendo em vista as condições socioculturais que nos encontramos, identificando os possíveis modos do exercício filosófico.

Sabendo da importância da Filosofia e do Filosofar para os jovens do ensino médio e do quanto possibilita o desenvolvimento do pensamento autônomo, entendemos ser um desafio possível o exercício filosófico com os jovens, porém, precisamos repensar o modo como estamos trabalhando. Uma alternativa é trabalhar a disciplina de filosofia a partir de seus problemas, contextualizando a realidade dos estudantes e envolvendo-os na problematização e conceituação, tornando as aulas de filosofia uma experiência filosófica.

Assim, precisamos considerar como importantes recursos didático-pedagógico para as aulas de filosofia, as tecnologias de comunicação e de informação, o cinema, as mídias digitais, pois estas nos proporcionam variadas possibilidades de atividades e assim podemos contextualizar a realidade e os interesses do estudante, envolvendo-o no processo do filosofar.

Neste sentido, esta pesquisa justifica-se pela necessidade de refletirmos, repensarmos e ressignificarmos o modo como concebemos e trabalhamos a filosofia com os jovens, considerando os novos interesses destes, a cultura contemporânea, novos modos de filosofar, pois a filosofia 
torna-se viva, ativa, se houver a problematização, a produção conceitual e o envolvimento este jovem em todo processo da experiência filosófica.

\section{ENSINO DE FILOSOFIA E CULTURA CONTEMPORÂNEA}

Sabemos que o ensino da Filosofia/filosofar requer leitura atenta dos clássicos, paciência para a sua compreensão, interpretação, releitura, produção textual, reflexão, pensamento racional, raciocínio coerente, problematização, conceituação. Mas inicialmente, cabe a reflexão: Ensinamos Filosofia ou ensinamos a Filosofar? Este questionamento nos remete, inevitavelmente, as reflexões feitas pelo Filósofo Kant, o qual defendia que não é possível ensinar filosofia, mas sim a filosofar. Para este Filósofo, a Filosofia é um saber inacabado e que está sempre aberto e em movimento. Conforme KANT apud ASPIS "[...] nunca se realizou uma obra filosófica que fosse duradoura em todas as suas partes em todas as suas partes. Por isso não se pode em absoluto aprender filosofia, porque ela ainda não existe"'. Neste sentido, de acordo com ASPIS,

[...]não é possível desunir filosofia de filosofar, pois os dois são uma mesma coisa. O filosofar é uma disciplina do pensamento, que ao ser operada vai produzindo filosofia e a filosofia é a própria matéria que gera o filosofar. São indissociáveis. A matéria filosofia separada do ato de filosofar é matéria morta, recheio de livro de estante. Para ser filosofia ela tem que ser reativada, reoperada, assim, reaparecendo a cada vez..[...] O movimento da razão a que chamamos filosofar se dá por intermédio de conceitos filosóficos e estes só são criados e recriados por meio do filosofar. Não há como ficar com uma coisa e dispensar a outra já que não são duas coisas e sim uma só. Não há o dilema filosofia ou filosofar. Filosofia é Filosofar e Filosofar é Filosofia[...] (ASPIS, 2004, p. 308)

Compreendemos a Filosofia como um conhecimento, uma área de saber, uma atitude. Seguindo a reflexão de MURCHO (2002), sobre a natureza da Filosofia e o seu Ensino, não podemos considerar a Filosofia como um corpo imenso de conhecimentos que tenhamos que adquirir, pois a Filosofia constitui-se por ideias, teorias e problemas.

No entanto, MURCHO afirma que "não podemos estudar Filosofia da Arte, sem nada saber de Arte; não podemos estudar Filosofia da Linguagem, sem nada saber de Linguística; não podemos estudar Metafísica, sem nada saber de Lógica; não podemos estudar Filosofia da Ciência sem nada saber de Ciência"3

É preciso entrarmos em contato com a tradição filosófica, conhecermos e discutirmos os problemas filosóficos, problemas estes que ao longo dos séculos foram já discutidos pelos filósofos. Neste sentido, a leitura atenta e paciente aos clássicos, e também aos filósofos contemporâneos, é imprescindível para a atividade filosófica, pois são neles que encontramos fundamentação teórica e reflexiva para podermos discutir problemas filosóficos e existenciais que se impõem até hoje. Desse modo, o estudo da filosofia começa pela compreensão gradual de um determinado problema ou conjunto de problemas filosóficos, onde procuramos saber o que alguns grandes filósofos, clássicos e contemporâneos pensaram sobre este problema (MURCHO, 2002, p.15).

No entanto, na condição de docente, muitas vezes nos deparamos com uma realidade 2 ASPIS, Renata Pereira Lima. O professor de filosofia: $O$ ensino de filosofia no ensino médio como experiência filosófica. Cadernos CEDES, 24(64). 2004. p. 308.

3 MURCHO, Desidério. A natureza da filosofia e o Ensino. Revista Educação, 27(02), 2002.p. 14. 
que causa preocupação, qual seja, o desinteresse e a indiferença dos estudantes pela disciplina de Filosofia. Então, inevitavelmente nos questionamos: o desinteresse dos estudantes decorre de quais motivos?

Percebemos que as frustrações e indiferença podem estar relacionadas ao fato de que estamos diante de uma nova realidade, uma nova cultura, um novo modo de ser e existir, pensar e se expressar.

A cultura contemporânea constitui-se socialmente, principalmente através dos meios de comunicação de massa, a internet, as redes sociais e as tecnologias digitais. A mídia caracterizase pela velocidade e superficialidade das informações, onde representações de objetos, fatos, realidades mostram-se resolvidas, prontas, simplificadas e sua compreensão é dada, na maioria vezes, de forma instantânea, não necessitando muita atenção do telespectador para investigação e deciframento (XAVIER, 2004, p.136). Neste sentido, a mídia e a internet, tornam-se muito mais atraentes para o jovem.

Conforme XAVIER (2004) "O fluxo de imagens, instrumento e alicerce de novas tecnologias dos meios de comunicação de massa, em especial a televisão, participa significativamente na constituição, manejo e controle da subjetividade" "4. Não somente a televisão, através de seus programas e filmes tem este poder de constituir, controlar, formar subjetividades e identidades, mas também a internet, as redes sociais, as mídias digitais, de modo geral, são consideradas imprescindíveis para estes jovens atualmente, tornando-os muitas vezes dependentes e alienados a ela. Hoje, para a maioria dos jovens, e para muitos adultos também, existir significa ser popular nas redes sociais, aparecer, exibir sua felicidade, e ter muitos "likes" em suas fotos e postagens.

Considerar que a cultura midiática e imagética traduz o modo como às relações socioculturais acontecem na contemporaneidade significa considerar que o ensino de Filosofia não pode ser estruturado somente na cultura letrada. Segundo OBIOLS apud XAVIER (2004) "O fracasso da Escola é devido à falta de sintonia com a linguagem e as expectativas dos jovens. Levar a sério este diagnóstico implica em investir em procedimentos que busquem sintonizar-se com a linguagem dos adolescentes valorizando seus recursos expressivos" 5 .

Neste sentido, é fundamental conhecermos os anseios e a cultura que perpassam as vivências juvenis, para então planejarmos um ensino de Filosofia que seja significativo. Talvez, ao pensar como concebemos a Filosofia e seu ensino tenhamos como articular a cultura contemporânea enquanto um potente indicador para o trabalho filosófico. Ou seja, a Filosofia e seu ensino exigem a articulação de aspectos que podem definir o sentido do que pode ser a Filosofia, e qual sua relação com o filosofar entre os jovens.

Encontramos a defesa de MURCHO (2002) assim como de muitos outros filósofos na tradição filosófica, de que a Filosofia é aquela área do conhecimento, área de saber, que contribui para o desenvolvimento do pensamento autônomo,

[...] contribui para o estudante pensar com mais clareza, sabendo traçar distinções, sabendo detectar e evitar erros de raciocínio, sabendo avaliar opiniões opostas e a tomar decisões informadas e refletidas. Isto é de importância fundamental para a vida pública e cultural de qualquer sociedade[...](MURCHO, 2002, p.15)

\section{A AULA COMO EXPERIÊNCIA FILOSÓFICA}

4 XAVIER, Ingrid Muller. Filosofia em tempos de adrenalina. KOHAN, Walter O. (org). Filosofia: caminhos para seu ensino. Rio de Janeiro: DP\&A, 2004.p.136; p.150

5 XAVIER, Ingrid Muller. Filosofia em tempos de adrenalina. KOHAN, Walter O. (org). Filosofia: caminhos para seu ensino. Rio de Janeiro: DP\&A, 2004. p.150, 
[...] se são múltiplas as filosofias, se são variados os estilos do filosofar, múltiplas e variadas são também as perspectivas do Ensinar a filosofia e o filosofar. Assim, quando tratamos do Ensino de Filosofia é necessário que tomemos uma posição, que nos coloquemos no campo de uma determinada concepção de filosofia. E, fundamental, que deixemos isso claro; que evidenciemos a posição filosófica com base na qual pensamos e ensinamos[...] (GALLO, 2012, p. 39)

No momento em que o estudante encontra-se envolvido numa situação que problematiza e exige reflexão sobre as questões filosóficas, ele toma para si o problema, entende como seu, pensa como resolvê-lo, criando a experiência filosófica, a qual proporciona autonomia de pensamento, no sentido de que o estudante não apenas lê, mas entende as condições nas quais a Filosofia é um corpus de saber, ao mesmo tempo em que filosofa, acontece a experiência singular de pensamento.

Nesse sentido, precisamos admitir que "o princípio, a origem do pensamento é sempre uma experiência sensível"6. E esta experiência sensível é que deve ser vivenciada pelo estudante e também por nós, professores, no momento em que ela acontece, no momento que ela surge. Conforme GUIDO; GALLO; KOHAN,

[...] a emancipação intelectual, consiste no exercício do direito aos próprios problemas, na experimentação sensível dos problemas singulares. Apenas com isto será possível experimentar um pensamento original, que seja engendrado no próprio ato de pensar. Experimentar os próprios problemas: eis a única condição para o exercício do pensamento próprio, de um pensamento autônomo, não tutelado, não pré determinado[...] (CARVALHO; CORNELLI, 2013, p. 125)

O professor de filosofia deve ser o provocador de experiências, quem suscita os problemas filosóficos, os quais devem estar contextualizados com a realidade e os interesses dos estudantes e do mesmo modo, o orientador para que os alunos achem a solução destes problemas.

De acordo com ASPIS,

[...]nas aulas de filosofia como experiência filosófica, o professor é um orientador, ele põe à disposição para os seus alunos os instrumentos que conhece para uma disciplina filosófica no pensamento. Cria com os alunos um grupo, uma equipe, que tem um objetivo comum: encontrar saídas para um problema elaborado por eles mesmos, de seu interesse, por meio da investigação e do estudo filosófico[...] (ASPIS, 2004, p. 311)

O professor de filosofia deve propiciar em sua sala de aula, um ambiente de investigação de problemas filosóficos, um ambiente de questionamento e de experiências filosóficas. Segundo ASPIS,

6 GUIDO, Humberto; GALLO, Silvio; KOHAN, Walter Osmar. Princípios e possibilidades para uma metodologia filosófica do ensino de filosofia: história, temas, problemas. CARVALHO, Marcelo; CORNELLI, Gabriele (Org). Ensinar Filosofia. Cuiabá: Central de Texto, 2013.p. 122 
[...] 0 professor de Filosofia vai ensinar a pensar filosoficamente, a organizar perguntas num problema filosófico, ler e escrever filosoficamente, a investigar e dialogar filosoficamente, avaliar filosoficamente, criar saídas filosóficas para o problema investigado [...](ASPIS, 2004, p. 310)

Para ASPIS "o professor de filosofia é aquele que cria instrumentos e estratégias, seleciona textos, cria atividades e jogos, com o objetivo de provocar, envolver o jovem no processo do filosofar" ". Neste sentido, nós professores, pensamos novos modos de filosofar, novas metodologias, novos recursos didático-pedagógicos, que facilitam e proporcionam ao jovem do ensino médio a experiência de pensamento filosófico.

\section{RECURSOS DIDÁTICO-PEDAGÓGICOS PARA AS AULAS DE FILOSOFIA}

Contemporaneamente, o ensino de Filosofia precisa articular os dados da cultura que compõem com as tecnologias de comunicação e informação, a internet, mídias digitais, cinema, entre outros artefatos socioculturais, às multiplicidades existenciais dos jovens que habitam o território escolar. Deste modo, é necessário que a teoria e prática filosófica se apropriem dos problemas filosóficos para criar vínculos de afeto com a singularidade de pensar os problemas e soluções mediante os artefatos oriundos da cultura midiática-imagética.

As (TICS) Tecnologias de Comunicação e de Informação podem ser um importante recurso, uma ferramenta didático-pedagógica para as aulas de filosofia, pois faz parte da realidade da maioria dos estudantes, nos aproximando dos interesses destes e possibilitando o seu envolvimento na experiência filosófica.

Segundo TOMAZETTI e MORAES

Com a crescente emergência das Tecnologias da informação e da comunicação, as criações filosóficas atuais ganham uma nova forma de expressão, uma nova roupagem e novas formas de percepção, sobretudo com a facilidade do compartilhamento de informação e do conhecimento cada vez mais aberto e fluido. (TOMAZETTI; MORAES, 2014, p. 346)

Desse modo, nós professores de filosofia, compreendemos o "novo", estamos abertos a mudanças e podemos aproveitar as vantagens das Tecnologias de comunicação e informação, articulando estas ao conhecimento filosófico.

O momento exige um exercício de reflexão sobre os novos modos de fazer filosofia, de filosofar, e isto não quer dizer que tenhamos que deixar de lado o que é próprio da filosofia, o que a constitui, a leitura de textos filosóficos, dos clássicos, a leitura filosófica de textos, e a produção escrita. Isto faz parte da cultura letrada, no entanto, não podemos abandoná-la e sim fazer uma mediação entre esta e a cultura midiática, o que, sem dúvida, representa um desafio.

De acordo com OLIVEIRA apud TOMAZETTI; MORAES

7 ASPIS, Renata Pereira Lima. O professor de filosofia: O ensino de filosofia no ensino médio como experiência filosófica. Cadernos CEDES, 24(64). 2004. p. 316 
[...] vemos a relação entre os meios massivos e a escola de ensino médio. Esta [...] tem de aceitar a tarefa da busca de novas formas de estabelecer mediações entre seus alunos e um universo de imagens que Ihes cercam diariamente - o que não significa, por outro lado, abandonar a cultura escrita. Trata-se, pois, de não se cair no discurso da negação, rejeitando completamente o novo cenário cultural que se nos apresenta, tal como se a cultura midiática e a cultura escolar representassem dois campos opostos e inconciliáveis [...] (TOMAZETTl; MORAES, 2014, p. 108)

Neste sentido, assim como os livros impressos ou a escrita no papel, os ambientes virtuais e as TICs em geral, também podem configurar-se em ferramentas, meios e recursos para ensinar e aprender filosofia e servirem de aliados para exercícios de leitura e escrita filosófica (MORAES; TOMAZETTI, 2014, p. 348).

É importante conhecermos o que são as tecnologias de comunicação e informação, entendermos quais são as suas vantagens e desvantagens e descobrir a melhor forma de explorar as suas facilidades e possibilidades para as aulas de filosofia. Outra importante possibilidade é a utilização de filmes (cinema) para trabalhar a disciplina de filosofia.

Conforme KENSKI apud BASTIANI; MORAES,

[...] favoráveis ou não, é chegado o momento em que nós, profissionais da educação, que temos o conhecimento e a informação como nossas matérias-primas, enfrentarmos os desafios oriundos das novas tecnologias. Esses enfrentamentos não significam a adesão incondicional ou a oposição radical ao ambiente eletrônico, mas, ao contrário, significam criticamente conhecê-los para saber de suas vantagens e desvantagens, de seus riscos e possibilidades, para transformá-los em ferramentas e parceiros em alguns momentos e dispensá-los em outros instantes [...] (KENSKI apud BASTIANI; MORAES, 2012, p. 61)

Associar Arte e Filosofia pode tornar o ensino de filosofia muito mais atraente aos estudantes. O cinema é uma das produções artísticas que tem poder de comunicação universal, despertando o interesse dos estudantes pelas suas imagens, fotografia, linguagens, principalmente se vier ao encontro dos seus interesses. O filme inteligente e bem produzido, desperta emoções, suscita a dúvida, causa surpresas, problematiza conceitos inerentes à existência humana, como: verdade, dor, angustia, justiça, injustiça, morte, felicidade, entre outros, nos fazendo questionar e perspectivar nosso ponto de vista.

Conforme VEIVERBERG,

[...] os elementos visuais dão do filme um poder de comunicação. Ao vermos um filme, podemos ser levados para qualquer lugar, pois não há um senso de espaço, já que sentimos com muita proximidade o que ocorre nas cenas. O cinema agrega imagem, movimento e linguagem. Torna possível o que parece impossível, 
torna incrivel o que parece banal, questiona a realidade, possibilita as dúvidas e retrata as diferenças. Questiona a verdade, a dor e a angústia, a justiça, injustiça, a morte, a felicidade a violência, e todas as dimensões da existência humana, e a filosofia, por sua vez, fez ao longo de sua história e até os dias de hoje, destas dimensões humanas objeto da reflexão e compreensão racional [...](CRUZ; MARÇAL, 2012, p. 70)

Um filme pode ser lido e interpretado de diferentes maneiras, como afirma o texto, mas o que o torna filosófico é o fato de o analisarmos de um ponto de vista conceitual. É através das imagens que o cinema, explicita as ideias, através das dimensões racional e afetiva. A arte, assim como a filosofia, pode inspirar, desesperar, espantar, emocionar, encantar. Neste sentido, utilizar o cinema, filmes, como recurso ou ferramenta didática, pode ser uma alternativa para o ensino de filosofia e o filosofar, pois em muito pode facilitar o processo de sensibilização e compreensão do estudante quanto à temática proposta.

A importância destas alternativas como, a arte, cinema, as tecnologias de comunicação e informação para o ensino de filosofia, vale o quanto elas podem envolver o interesse do estudante nas aulas de filosofia. No entanto, é imprescindível a leitura de textos filosóficos e a produção escrita, pois ambos constituem o exercício filosófico proporcionando ao jovem instrumentos para criar e resolver problemas filosóficos.

Na escrita de Heuser, encontramos a compreensão da leitura como sendo um dos modos mais aprazíveis de acesso ao conhecimento, ela possibilita ampliar os horizontes, mudar as perspectivas, viajar no tempo, entrar em contato com as ideias dos filósofos clássicos, além de criar mais vida nas próprias vidas (HEUSER, 2016, p.10)

Nós, como filósofos, professores de filosofia, alimentamos uma paixão pela leitura, geralmente pelos filósofos clássicos, os quais proporcionam grande parte dos fundamentos teóricos para a nossa prática. É necessário termos o hábito da leitura, pois quanto mais lermos, tanto os clássicos, como os filósofos da atualidade, mais teremos propriedade para falarmos e escrevermos sobre temas ou problemas que, desde a antiguidade até a atualidade são pertinentes. Associada à leitura temos a escrita, sendo graças a esta, possível a nós, esse contato com os sábios (HEUSER, 2016 , p. 10). Esta paixão que nós temos pela leitura, é a que precisamos despertar no estudante.

A leitura, para a filosofia, significa saber decodificar o código escrito, é problematização, reflexão, interpretação e desenvolvimento de consciência crítica sobre o que é lido, é produção conceitual. Não é, portanto, um processo mecânico, maçante, é uma conversa, um diálogo com o autor, onde ocorre o choque com o desconhecido, gerando pesquisa e a construção de um novo conhecimento, sendo possível, posteriormente a produção da escrita filosófica. Tanto a leitura quanto a escrita (produção de textos) na filosofia, são formas de instrumentalizar o estudante, de provocar nele uma experiência filosófica, de fazê-lo pensar, refletir diante de problemas e questionamentos que ele mesmo se impõe, criando, assim, possibilidades de desenvolver sua autonomia de pensamento.

\section{CONSIDERAÇÕES FINAIS}

Levando em consideração os aspectos investigados, percebemos que o exercício filosófico com o jovem do ensino médio, oriundo de uma cultura permeada pelas tecnologias digitais, torna-se um desafio para nós professores de filosofia. Um desafio por que a atividade filosófica requer leitura, paciência, atenção, compreensão e interpretação, problematização, conceituação, porém, o que constitui a cultura do jovem contemporâneo, vai no sentido inverso ao que propõe a filosofia. É uma cultura da imagem, da mídia, tecnologias digitais, velocidade e super- 
ficialidade de informações, não necessitando de muita atenção para a sua compreensão, e na maioria das vezes, o jovem não está interessado em atividades que requeiram atenção e leitura, não está interessado em filosofia.

Neste sentido, sabendo do quão importante é a atividade filosófica para o desenvolvimento do pensamento autônomo do jovem na nossa sociedade atual e, o quanto ela proporciona a este uma compreensão e interpretação crítica da realidade em que estão inseridos, é fundamental que repensemos nossa prática pedagógica e nossos modos de trabalhar a filosofia. Deste modo, a atividade filosófica contribui para que os jovens sejam atuantes nesta sociedade, sujeitos da própria história, sujeitos estes, com formação ética e política, o que faz toda diferença no atual momento social em que vivemos.

É necessário que o professor repense suas concepções sobre o que é a filosofia e possa tornar sua sala de aula um ambiente de investigação filosófica, de questionamento, de problematização, um ambiente que proporcione experiências filosóficas a partir de problemas filosóficos que tenham relação direta com a realidade destes jovens. As tecnologias de informação e comunicação, as mídias digitais, o cinema, a internet, são ferramentas didático- pedagógicas, que nos oferecem variadas possibilidades de explorar o saber filosófico, e podem despertar o interesse deste jovem e proporcionar o seu envolvimento em todo processo do filosofar.

Assim, entendemos ser a atividade filosófica com o jovem do ensino médio, um desafio possível, porém, é imperativo que o professor conheça e contextualize a realidade deste jovem, não ignore e compreenda essa transformação cultural que ocorre, tenha consciência de que os jovens de hoje não são como os jovens de antigamente, e possa rever, adaptar e ressignificar sua prática pedagógica, seus modos de filosofar, possa recriar seus próprios conceitos sobre ensino de filosofia e filosofar. E este também é um problema filosófico que se apresenta e requer uma solução!

\section{REFERÊNCIAS}

ASPIS, Renata Pereira Lima. O professor de filosofia: $O$ ensino de filosofia no ensino médio como experiência filosófica. Cadernos CEDES, 24(64). 305-320, 2004.

ASPIS, Renata Pereira Lima. Ensino de Filosofia e resistência e sub-versões e. Revista Polyphonía, 23 (2), 2012.

BASTIANI, Tania Mara de.; MORAES, Simone Becher Araujo. Ensinar e Aprender Filosofia no contexto das Tecnologias da informação e da comunicação: realidade, formação e aprendizagem. IX ANPED SUL- Seminário de pesquisa em Educação da Região Sul, 2012.

BRASIL. MINISTÉRIO DA EDUCAÇÃO(MEC). Secretaria de Educação Básica. Orientações curriculares nacionais para o ensino médio. Ciências Humanas e suas tecnologias. Brasília: MEC/SEB, 2006.

CARVALHO, Marcelo; CORNELLI, Gabriele (Org). Ensinar Filosofia. Cuiabá, MT: Central de texto, 2013.

CERLETTI, Alejandro A. Ensinar Filosofia: da pergunta filosófica à proposta metodológica. In: KOHAN, Walter O. (org). Filosofia: caminhos para seu ensino. Rio de Janeiro: DP\&A, p. 19-43, 2004.

CERLETTI, Alejandro A. O ensino de filosofia como problema filosófico. Trad. de Ingrid Muller Xavier. Belo Horizonte: Autêntica, 2009.

CORNELLI, Gabriele; DANELON, Márcio; GALLO, Sílvio. Filosofia do ensino de Filosofia. Petrópolis-RJ: Vozes, 2003. (Série Filosofia na Escola, 7). 
DELEUZE, Gilles; GUATTARI, Félix. O que é a filosofia? Rio de Janeiro: Ed. 34, 2010.

DOUAILLER, Stéphane. A filosofia que começa: desafios para o ensino da filosofia no próximo milênio. In: GALLO, S.;DANELON, Márcio; CORNELLI, Gabriele.(Orgs.). Filosofia do Ensino de Filosofia. Petrópolis-RJ: Vozes, 2003.

FAVARETTO, Celso. Filosofia, Ensino e Cultura. In: KOHAN, Walter O. (Org.). Filosofia: caminhos para seu ensino. Rio de Janeiro: DP\&A, 2004.

FÁVERO, Altair. et al. O Ensino de Filosofia no Brasil: um mapa das condições atuais. Cadernos CEDES, Campinas-SP, v.24, n. 64, set.- dez. 2004.

GALLINA, Simone Freitas da Silva. O Ensino de Filosofia e a criação de conceitos. Cadernos CEDES, 24(64). p.359-371, 2004.

GALLINA, Simone Freitas da Silva. Invenção e aprendizagem em Gilles Deleuze. Campinas, 2008.

GALLINA, Simone Freitas da Silva. TOMAZETTI, Elisete Medianeira. Qual a relação do Ensino de Filosofia com a Cultura Juvenil? (Orgs.). Territórios da prática filosófica. Santa Maria: Editora da UFSM, 2009, p. 171-188.

GALLO, Sílvio; KOHAN, Walter. O. Filosofia no ensino médio. Petrópolis-RJ: Vozes, 2000. (Série Filosofia na Escola, 6).

GALLO, Sílvio. Metodologia do ensino de filosofia: uma didática para o Ensino Médio. Campinas, SP: Papirus, 2012.

GALLO, Sílvio. O problema e o conceito: Em torno de um 'método regressivo' para o ensino de Filosofia. Da filosofia como disciplina: Desafios e perspectivas. São Paulo: Loyola, 201 1, pp.67-95.

GALLO, Sílvio. Filosofia na educação básica e a formação do professor. In: Trajetórias e processos de ensinar e aprender: Práticas e didáticas. Porto Alegre: Ed. da PUC-RS, 2008, v.2, pp.636-645.

GALLO, Sílvio. O problema e a experiência do pensamento: implicações para o ensino de filosofia. Filosofia, aprendizagem, experiência. Belo Horizonte: Autêntica, 2008, pp. 115-130.

GALLO, Sílvio. A filosofia e o seu ensino: conceito e transversalidade. Filosofia no Ensino médio: Temas, Problemas e propostas. São Paulo: Loyola, 2007, pp. 15-36.

GALLO, Sílvio. A especificidade do ensino de filosofia: em torno de conceitos. Filosofia e ensino em debate. ljuí: Ed. da UNIJUÍ, 2002, pp. 193-210.

GUIDO, Humberto; GALLO, Silvio; KOHAN, Walter Osmar. Princípios e possibilidades para uma metodologia filosófica do ensino de filosofia: história, temas, problemas. CARVALHO, Marcelo; CORNELLI, Gabriele (Org). Ensinar Filosofia. Cuiabá: Central de Texto, 2013.

GOTO, Roberto; SILVEIRA, Renê J. T. (Org.). Filosofia no Ensino Médio - Temas, problemas e propostas. São Paulo: Loyola, 2007.

HEUSER, Esther. Modos de Ler Filosofia: uma conversa com iniciantes e iniciados. Revista Digital de Ensino de Filosofia, 02(01), 2016, Santa Maria.

MURCHO, Desidério. A natureza da filosofia e o Ensino. Revista Educação, 27(02), 2002. 
OBIOLS, Guillermo. Uma introdução ao ensino da filosofia. Trad. de Sílvio Gallo. ljuí-RS: Unijuí, 2002.

PAIS, José Machado. Culturas Juvenis. Lisboa: Imprensa Nacional Casa da Moeda, 1993.

PORTA, M.A.G., A filosofia a partir de seus problemas. São Paulo, Loyola, 2002.

SILVA, Tomaz Tadeu da.(org). Alienígenas na sala de aula: uma introdução aos estudos culturais em Educação. Petrópolis/RJ: Vozes, 1995.

TOMAZETTI, Elisete Medianeira (org). Ensino de Filosofia - experiências, Problematizações e Perspectivas. Curitiba-PR: Appris, 2015.

TOMAZETTI, Elisete M. (Org.) Filosofia no Ensino Médio: experiências com cinema, teatro, leitura e escritura a partir do PIBID. São Leopoldo: Oikos, 2012.

TOMAZETTI, Elisete Medianeira. A relação dos jovens com a filosofia no Ensino Médio. Revista Philósophos, 12 (1). 57-78, 2007.

TOMAZETTI, Elisete M.; MORAES, Simone Becher Araujo. Ensino de Filosofia e TIC: experiências do PIBID. Revista Intersaberes, 9 (18). 345-360, 2014.

XAVIER, Ingrid Muller. Filosofia em tempos de adrenalina. KOHAN, Walter O. (org). Filosofia: caminhos para seu ensino. Rio de Janeiro: DP\&A, 2004. 